\title{
Separation of a Multitracer from an Au Target Irradiated with High-Energy Heavy Ions by Means of a Supported Liquid Membrane
}

\author{
Shizuko Ambe $\dagger$, Masako Iwamoto, Haruka MaEda and Fumitoshi Ambe \\ The Institute of Physical and Chemical Research (RIKEN), \\ Wako, Saitama 351-01, Japan
}

\begin{abstract}
The transport of $\mathrm{Au}(\mathrm{III})$ and 19 other metal ions through a tributyl phosphate (TBP)-decalin membrane supported on a microporous polytetrafluoroethylene sheet was studied in order to establish a procedure for removing Au(III) ions from acid solutions of a gold target irradiated by high-energy heavy ions, leaving a multitracer solution in a carrier- and saltfree state. Distilled water was used as a stripping agent. A feed solution of $3 \mathrm{~mol} \mathrm{dm}^{-3} \mathrm{HCl}$ gave the highest transport rate in the $0.1-8 \mathrm{~mol} \mathrm{dm}^{-3} \mathrm{HCl}$ range. The transport of carrier-free radioisotopes of $\mathrm{Sc}, \mathrm{Fe}, \mathrm{Zr}, \mathrm{Nb}, \mathrm{Te}$, and $\mathrm{Hf}$ was observed for $8 \mathrm{~mol} \mathrm{dm}^{-3} \mathrm{HCl}$ and that of $\mathrm{Fe}, \mathrm{Zr}, \mathrm{Nb}$, and $\mathrm{Te}$ for 5 and $6 \mathrm{~mol} \mathrm{dm}^{-3} \mathrm{HCl}$, while their transport was not detected for 0.1 and $1 \mathrm{~mol} \mathrm{dm}^{-3} \mathrm{HCl}$ feed solutions and was small with $3 \mathrm{~mol} \mathrm{dm}^{-3} \mathrm{HCl}$. The $3 \mathrm{~mol} \mathrm{dm}^{-3} \mathrm{HCl}$ solution is considered to be the best feed solution for preparing a multitracer from an Au target, because of the large transport rate of $\mathrm{Au}(\mathrm{III})$ and the negligible transport of other elements. The transport rates of $\mathrm{Au}(\mathrm{III})$ ions from $0.2-2 \mathrm{~mol} \mathrm{dm}^{-3}$ $\mathrm{HNO}_{3}$ solutions are smaller than those from $1-6 \mathrm{~mol} \mathrm{dm}^{-3} \mathrm{HCl}$. On the basis of these observations, a practical procedure was established for preparing a multitracer solution from a heavy-ion-irradiated Au target.
\end{abstract}

Keywords Supported liquid membrane, TBP-decalin, transport, Au(III), metal ion, multitracer

A large number of radioactive nuclides, useful as tracers, are produced in targets by high-energy heavy-ion irradiation. We demonstrated that the simultaneous use of these tracers provides not only an efficient acquisition of data concerning many elements, but also the acquisition of data under the same experimental conditions. ${ }^{1-12}$ We have been studying how to remove the target materials from acid solutions of the targets while leaving as many types of and as much carrier-free radioactive nuclides as possible in solutions. We previously reported on conventional radiochemical procedures for preparing multitracer solutions from $\mathrm{Au}, \mathrm{Ag}, \mathrm{Cu}$, and $\mathrm{Fe}$ targets irradiated by high-energy heavy-ion beams. ${ }^{13-15}$

Separation by means of supported liquid membranes is considered to be one of the most useful methods for the removing radioactive nuclides, because: (i) the simplicity of operation, (ii) the feasibility of concentrating radioactive nuclides into a small volume of solution, and (iii) the necessity of a far smaller amount of extractant than in conventional solvent extraction, resulting in little organic radioactive waste. These advantages have promoted extensive applications of the supported liquid-membrane method for separating radioactive elements. ${ }^{16-23}$ Recently, Fu et al. reported on the transport of $\mathrm{Au}$ (III) ions through a supported liquid membrane impregnated with trioctylamine. ${ }^{24}$

We have already briefly reported on the successful removal of the target material $\mathrm{Au}$ from acid solutions using a tributyl phosphate (TBP)-decalin membrane. ${ }^{25}$ Here we describe in detail the transport behavior of not only $\mathrm{Au}(\mathrm{III})$ ions, but also various radioactive nuclides produced in the $\mathrm{Au}$ target from $\mathrm{HCl}$ and $\mathrm{HNO}_{3}$ feed solutions through a TBP-decalin membrane supported on a microporous polytetrafluoroethylene sheet. Permeation was carried out under various conditions by changing the kind of stripping solution, the concentrations of $\mathrm{HCl}$ and $\mathrm{HNO}_{3}$ in feed solutions and the concentration of TBP in the membrane. TBP was adopted as the carrier in the membrane because Au has the largest distribution coefficient among all of the elements reported for solvent extraction by TBP from $1-12 \mathrm{~mol} \mathrm{dm}^{-3} \mathrm{HCl}$ and $1-3 \mathrm{~mol} \mathrm{dm}^{-3} \mathrm{HNO}_{3}{ }^{26}$

The procedure developed in this work was applied to the actual preparation of a multitracer solution from an $\mathrm{Au}$ target irradiated by a $135 \mathrm{MeV} /$ nucleon ${ }^{14} \mathrm{~N}$ beam accelerated by the RIKEN Ring Cyclotron. The merits and demerits of the method are discussed in comparison with other separation methods used in our previous experiments (reduction of $\mathrm{Au}$ (III) ions to metal and solvent extraction of $\mathrm{Au}(\mathrm{III})$ ions with ethyl acetate).

† To whom correspondence should be addressed. 


\section{Experimental}

\section{Preparation of feed solutions}

Disks of Au $(100-300 \mu \mathrm{m} \times 23 \mathrm{~mm} \phi)$ were irradiated by a $135 \mathrm{MeV} /$ nucleon ${ }^{12} \mathrm{C},{ }^{14} \mathrm{~N}$, or ${ }^{16} \mathrm{O}$ beam accelerated by the RIKEN Ring Cyclotron. An Au target containing various kinds of radioactive nuclides produced by nuclear-fragmentation reactions was dissolved in aqua regia. The solution was evaporated to dryness in a rotary evaporator under reduced pressure. The residue was dissolved in dilute $\mathrm{HCl}$ or $\mathrm{HNO}_{3} . \mathrm{HCl}(0.1-8$ mol dm$\left.{ }^{-3}\right)$ and $\mathrm{HNO}_{3}\left(0.2-2 \mathrm{~mol} \mathrm{dm}^{-3}\right)$ containing 10 $170 \mathrm{mg}$ of $\mathrm{Au}$ were used as feed solutions.

\section{Stripping solutions}

Distilled water, $0.5 \mathrm{~mol} \mathrm{dm}^{-3}$ sodium thiocyanate, and $1 \mathrm{~mol} \mathrm{dm}^{-3}$ sodium bicarbonate solutions were examined as stripping solutions.

\section{Supported liquid membrane}

The microporous sheet used as the support for TBPdecalin was polytetrafluoroethylene, Fluoropore FP-045 (Sumitomo Electric Ind.), with an average pore size of $0.45 \mu \mathrm{m}, 75 \%$ porosity, and $0.08 \mathrm{~mm}$ thickness. A supported liquid membrane with a diameter of $24 \mathrm{~mm}$ was prepared by immersing the sheet in TBP-decalin solutions with TBP/decalin ratios of $0.135,0.27,1,2$, and 3 for at least $3 \mathrm{~d}$ until it became semitransparent. Before use, the sheet impregnated with TBP-decalin was rinsed by dipping it in distilled water with gentle shaking.

\section{Transport and $\gamma$-ray measurement}

The effect of the TBP concentration of the supported liquid membrane on the transport rate was studied as follows. Each of three supported liquid membranes with different TBP concentrations was fixed at the bottom of a Teflon vessel with a Teflon ring, and $20 \mathrm{~cm}^{3}$ of distilled water was added to each of these vessels as a stripping solution. The three Teflon vessels were placed in a $3 \mathrm{~mol} \mathrm{dm}-3 \mathrm{HCl}$ feed solution $\left(100 \mathrm{~cm}^{3}\right)$ containing $63.5 \mathrm{mg}$ of gold and radioactive nuclides. The feed solution in the outer vessel was stirred at $1000 \mathrm{rpm}$ using a magnetic stirrer at room temperature. The stripping solutions were stirred by circulating them at a rate of $3 \mathrm{~cm}^{3} \mathrm{~min}^{-1}$. Five cubic centimeters of the stripping solutions was withdrawn 0.5 and $1 \mathrm{~h}$ after the start of the permeation and subjected to $\gamma$-ray measurements. The photopeaks of $355.6 \mathrm{keV} \gamma$-rays emitted by ${ }^{196} \mathrm{Au}\left(T_{1 / 2}=\right.$ $6.18 \mathrm{~d})$ were measured with an intrinsic Ge detector.

In the experiment described below, a membrane with a TBP/decalin ratio of 0.27 was used. A Teflon vessel with a membrane at the bottom containing $25 \mathrm{~cm}^{3}$ of distilled water as a stripping solution was placed in $25 \mathrm{~cm}^{3}$ of a $3 \mathrm{~mol} \mathrm{dm}^{-3} \mathrm{HCl}$ feed solution containing $10 \mathrm{mg}$ of gold and radioactive nuclides. The feed solution in the outer vessel was stirred at $1000 \mathrm{rpm}$ with a magnetic stirrer at room temperature. The stripping solution was circulated at a rate of $3 \mathrm{~cm}^{3} \mathrm{~min}^{-1}$. A
Table 1 Transport rates of $\mathrm{Au}(\mathrm{III})$ ions through membranes with TBP/decalin (normalized by the value for the membrane with a TBP/decalin ratio of 1 )

\begin{tabular}{cc}
\hline TBP/decalin ratio & Relative transport rate \\
\hline 0.135 & 0.4 \\
0.27 & 1.0 \\
1 & 1.0 \\
2 & 0.8 \\
3 & 0.9 \\
\hline
\end{tabular}

portion of this circulating solution was trapped in a Teflon vessel set on the top of an intrinsic Ge detector for $\gamma$-ray measurements. Measurements of $10-20 \mathrm{~min}$ duration were automatically repeated for $200-300 \mathrm{~min}$, and the obtained $\gamma$-ray spectra were recorded on a magnetic disk. After permeation, the $\gamma$-ray spectra of all the stripping solutions and feed solutions were measured using the $\mathrm{Ge}$ detector for determining the percentage of permeation.

As a stability test of the membrane, permeation was continued for $2 \mathrm{~d}$ using $8 \mathrm{~mol} \mathrm{dm}^{-3} \mathrm{HCl}$ and $1 \mathrm{~mol}$ $\mathrm{dm}^{-3} \mathrm{HNO}_{3}$ feed solutions containing $170 \mathrm{mg}$ of $\mathrm{Au}$. The stripping solution was replaced with distilled water every time Au(III) transport became saturated.

The transport rates of $\mathrm{Au}$ and other carrier-free radioactive nuclides were determined by analyzing the $\gamma$ ray spectra on a FACOM M1800 computer at our institute. The nuclides were assigned on the basis of their $\gamma$-ray energies and half-lives.

\section{Results and Discussion}

\section{Stripping solutions}

Distilled water, sodium thiocyanate, and sodium bicarbonate solutions were examined in order to determine the most appropriate stripping solution for our purpose. The transport of Au(III) ions into distilled water proceeded smoothly, while precipitation of metallic $\mathrm{Au}$ was observed at the interface between the membrane and the two latter stripping solutions, resulting in a reduction of the transport rate. Therefore, distilled water was used as a stripping solution in the following experiments.

\section{Effect of the TBP concentration on $A u(I I I)$ transport}

Membranes with TBP/decalin ratios of $0.27-3$ gave no significant difference in terms of the transport rate of $\mathrm{Au}(\mathrm{III})$ ions within the limit of the experimental errors, while a membrane with a $\mathrm{TBP} /$ decalin ratio of 0.135 showed a smaller transport rate than the former. The results are shown in Table 1 . In the experiments described below, membranes with a TBP/decalin ratio of 0.27 were used.

\section{Transport from feed solutions of hydrochloric acid}

Figure 1 shows the transport of $\mathrm{Au}$ (III) ions from feed 


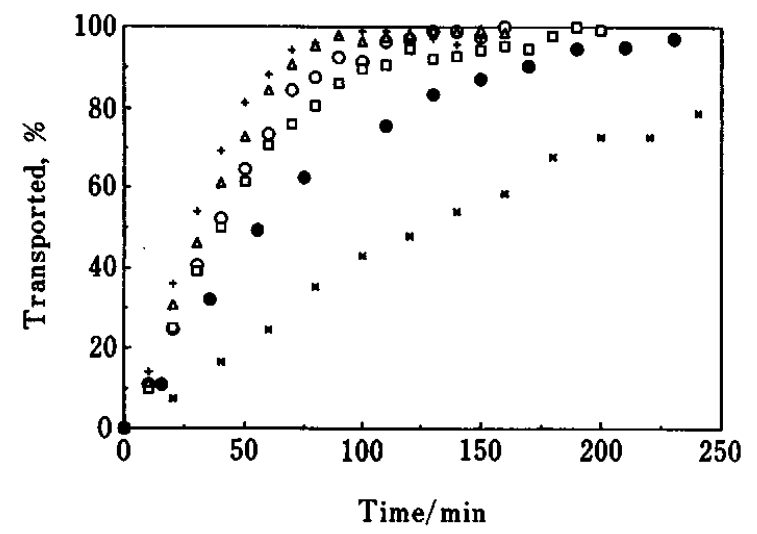

Fig. 1 The transport of $\mathrm{Au}(\mathrm{III})$ ions from feed solutions of 0.1 $(\bowtie), 1(O), 3(+), 5(\square), 6(\triangle)$, and $8(\odot) \mathrm{mol} \mathrm{dm}^{-3} \mathrm{HCl}$ to distilled water through a membrane with a TBP/decalin ratio of 0.27 .

solutions of various concentrations of hydrochloric acid. A feed solution of $3 \mathrm{~mol} \mathrm{dm}^{-3} \mathrm{HCl}$ gave the highest transport rate, though the difference in the initial transport rates was small among the $\mathrm{HCl}$ feed solutions in the $1-6 \mathrm{~mol} \mathrm{dm}^{-3}$ concentration range. More than 90\% of the $\mathrm{Au}(\mathrm{III})$ ions were transported to the stripping solution within $100 \mathrm{~min}$. On the other hand, the initial transport rates of $\mathrm{Au}(\mathrm{III})$ from feed solutions of 0.1 and $8 \mathrm{~mol} \mathrm{dm}^{-3}$ hydrochloric acid were smaller than those described above, though transport from these two feed solutions was observed to increase with time.

The permeation rate is expressed by

$$
\ln [C(t) / C(0)]=-A \varepsilon P t / V,
$$

where $C(t)$ is the concentration of metal ions in the feed solution at time $t$ (in this case, counts), $A$ the geometrical membrane area $\left(\mathrm{cm}^{2}\right), V$ the volume of the feed solution $\left(\mathrm{cm}^{3}\right), \varepsilon$ the membrane porosity, $t$ the permeation time (s), and $P$ the permeability coefficient $\left(\mathrm{cm} \mathrm{s}^{-1}\right)$. The permeability coefficients of the $\mathrm{Au}(\mathrm{IIII})$ ions were evaluated from the slope of straight lines obtained by plotting the logarithm of the concentration of $\mathrm{Au}$ (III) ions in the feed solution, $\ln [C(t) / C(0)]$, vs. the permeation time $t$. The permeability coefficients were estimated to be about $3 \times 10^{-3} \mathrm{~cm} \mathrm{~s}^{-1}$ for $\mathrm{Au}(\mathrm{III})$ in feed solutions of $1-6 \mathrm{~mol} \mathrm{dm}^{-3} \mathrm{HCl}$.

The liquid-membrane transport of Au(III) ions by a trioctylamine mobile carrier was studied by Fu et al..$^{24}$ The transport of Au(III) ions from a feed solution of $0.25 \mathrm{~mol} \mathrm{dm}^{-3} \mathrm{HCl}$ to a stripping solution of $1.0 \mathrm{~mol}$ $\mathrm{dm}^{-3} \mathrm{HClO}_{4}$ gave the maximum rate constant $k$, defined by $\ln [C(t) / C(0)]=-k t$. The rate constant is slightly larger than that obtained for feed solutions of 1-6 $\mathrm{mol} \mathrm{dm}{ }^{-3} \mathrm{HCl}$ in this work.

Radioactive nuclides of $\mathrm{Sc}, \mathrm{Fe}, \mathrm{Zr}, \mathrm{Nb}, \mathrm{Te}$, and $\mathrm{Hf}$ were also found in the stripping solution after $200 \mathrm{~min}$ of permeation from a feed solution of $8 \mathrm{~mol} \mathrm{dm}^{-3} \mathrm{HCl}$. The amounts of transported nuclides decreased along
Table 2 Transport (\%) of metal ions from $\mathrm{HCl}$ feed solutions

\begin{tabular}{crrrrrr}
\hline $\begin{array}{c}\text { Feed solution } \\
\left(\mathrm{mol} \mathrm{dm}^{-3} \mathrm{HCl}\right)\end{array}$ & $\mathrm{Sc}$ & $\mathrm{Fe}$ & $\mathrm{Zr}$ & $\mathrm{Nb}$ & $\mathrm{Te}$ & $\mathrm{Hf}$ \\
\hline 0.1 & 0 & 0 & 0 & 0 & 0 & 0 \\
1 & 0 & 0 & 0 & 0 & 0 & 0 \\
3 & 0 & 8 & 0 & 0 & 3 & 1 \\
5 & 0 & 100 & 10 & 40 & 30 & 0 \\
6 & 1 & 100 & 10 & 60 & 20 & 0 \\
8 & 20 & 100 & 30 & 70 & 10 & 5 \\
\hline
\end{tabular}

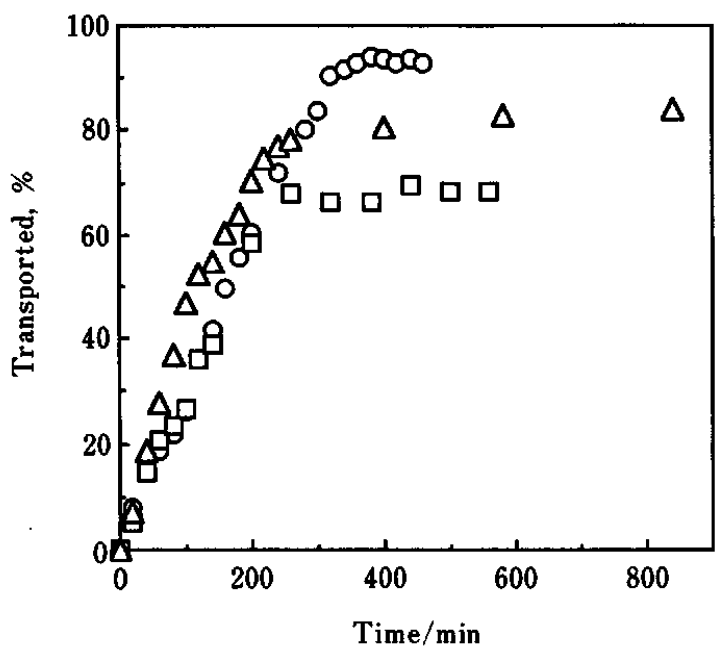

Fig. 2 Transport of $\mathrm{Au}(\mathrm{III})$ ions from feed solutions of $\mathbf{0 . 2}$ $(\mathrm{O}), 1(\triangle)$, and $2(\square) \mathrm{mol} \mathrm{dm}^{-3} \mathrm{HNO}_{3}$ to distilled water through a membrane with a TBP/decalin ratio of 0.27 .

with a decrease in the acid concentration of the feed solution (Table 2). No radioactivity due to these nuclides was detected for feed solutions of 0.1 and $1 \mathrm{~mol} \mathrm{dm}^{-3} \mathrm{HCl}$, and only small amounts of $\mathrm{Fe}, \mathrm{Te}$, and Hf were transported to the stripping solution from a $3 \mathrm{~mol} \mathrm{dm}^{-3} \mathrm{HCl}$ feed solution. In permeation using feed solutions of 5,6 , and $8 \mathrm{~mol} \mathrm{dm}^{-3} \mathrm{HCl}$, large amounts of $\mathrm{Fe}$ and $\mathrm{Nb}$ were removed from the feed solution. Since the $3 \mathrm{~mol} \mathrm{dm}^{-3} \mathrm{HCl}$ feed solution was found to realize a fast elimination of $\mathrm{Au}(\mathrm{III})$ ions, and to cause only a small loss in the above-mentioned nuclides during permeation, $3 \mathrm{~mol} \mathrm{dm}^{-3} \mathrm{HCl}$ is concluded to be the most suitable feed solution for preparing a multitracer solution from a gold target.

\section{Transport from nitric acid feed solutions}

Figure 2 shows the transport of $\mathrm{Au}$ (III) ions from feed solutions of $0.2,1$, and $2 \mathrm{~mol} \mathrm{dm}^{-3} \mathrm{HNO}_{3}$ which contained $10 \mathrm{mg}$ of $\mathrm{Au}$. It was found that the acid concentration of the feed solutions only slightly influenced the initial rates of the transport of $\mathrm{Au}$ (III) ions; however, the transport reached saturation after 70,80 , and $90 \%$ of $\mathrm{Au}(\mathrm{III})$ ions had been transported from feed solutions of 2, 1 and $0.2 \mathrm{~mol} \mathrm{dm}^{-3} \mathrm{HNO}_{3}$, respectively. The perme- 


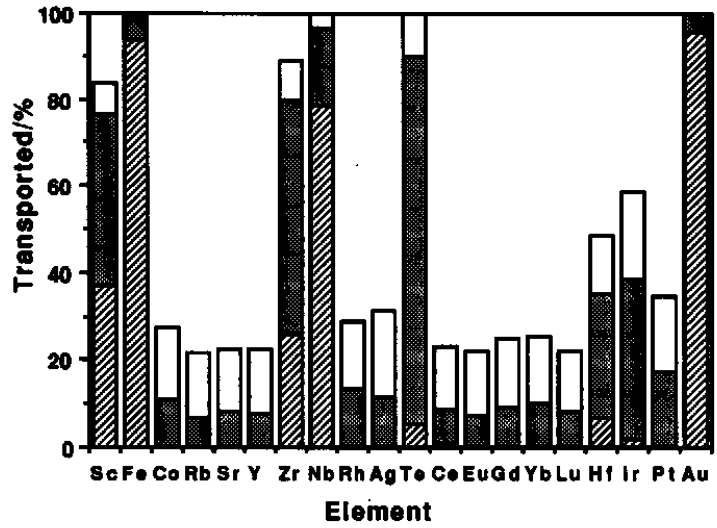

Fig. 3 Percentage distribution of metal ions in the first ( $\square)$, second (圈), and third ( $\square$ ) stripping solutions after transport from a feed solution of $8 \mathrm{~mol} \mathrm{dm}^{-3} \mathrm{HCl}$ through a membrane with a TBP/decalin ratio of 0.27 for $30 \mathrm{~h}$.

ability coefficient for $\mathrm{Au}(\mathrm{III})$ ions from the solutions was determined to be $7 \times 10^{-4} \mathrm{~cm} \mathrm{~s}^{-1}$, which is much smaller than that from $1-6 \mathrm{~mol} \mathrm{dm}^{-3} \mathrm{HCl}$ described above. Namely, the transport rates of $\mathrm{Au}(\mathrm{III})$ ions from the $\mathrm{HNO}_{3}$ feed solutions are smaller than those from $1-8$ mol dm ${ }^{-3} \mathrm{HCl}$ feed solutions. The radioactivities of nuclides other than $\mathrm{Au}$ in the stripping solutions were negligible with $\mathrm{HNO}_{3}$ feed solutions.

\section{Stability of the membranes}

In order to estimate the stability of the supported liquid membrane, permeation was performed for a long time using a feed solution of $8 \mathrm{~mol} \mathrm{dm}^{-3} \mathrm{HCl}$ containing $170 \mathrm{mg}$ of $\mathrm{Au}$ accompanied by a replacement of the stripping solution with fresh distilled water. Figure 3 shows the percentage distribution of each element in the first, second, and third stripping solutions collected during $0-300,300-1300$, and $1300-1800 \mathrm{~min}$, respectively. Most of the $\mathrm{Au}$ (III) ions were found in the first stripping solution and the rest in the second stripping solution. The third stripping solution showed no $\mathrm{Au}$ (III) ion color and no $\mathrm{Au}$ radioactivity, indicating complete transport of $\mathrm{Au}(\mathrm{III})$ ions to the first and second solutions. As described above, in the first stripping solution large fractions of $\mathrm{Fe}$ and $\mathrm{Nb}$ and small fractions of $\mathrm{Sc}, \mathrm{Zr}, \mathrm{Te}, \mathrm{Ce}, \mathrm{Hf}$, and Ir were found. In the second stripping solution, nuclides of $\mathrm{Co}, \mathrm{Rb}, \mathrm{Sr}, \mathrm{Y}, \mathrm{Rh}, \mathrm{Ag}, \mathrm{Eu}$, $\mathrm{Gd}, \mathrm{Yb}, \mathrm{Lu}$, and $\mathrm{Pt}$ were found together with those of Sc, $\mathrm{Fe}, \mathrm{Zr}, \mathrm{Nb}, \mathrm{Te}, \mathrm{Ce}, \mathrm{Hf}$, and Ir, which were already partly found in the first stripping solution; namely, all of the elements present in the feed solution were found in the second stripping solution. Among them, Te showed a marked increase in the second stripping solution. The fractions of each element transported to the third stripping solution were almost the same as each other. These results suggest that the membrane lost its selectivity at the end of the second permeation stage.

Similarly, permeation from a $1 \mathrm{~mol} \mathrm{dm}{ }^{-3} \mathrm{HNO}_{3}$ solution containing $170 \mathrm{mg}$ of $\mathrm{Au}$ was carried out by

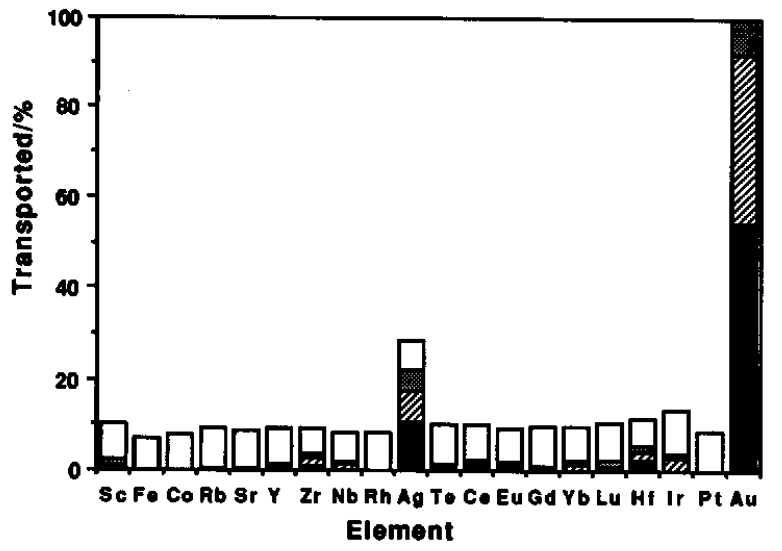

Fig. 4 Percentage distribution of metal ions in the first ( $\mathbf{\square}$ ),

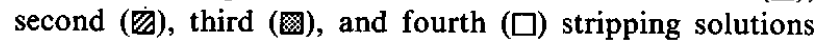
after transport from a $1 \mathrm{~mol} \mathrm{dm}^{-3} \mathrm{HNO}_{3}$ feed solution through a membrane with a TBP/decalin ratio of 0.27 for $46 \mathrm{~h}$.

occasionally replacing the stripping solutions with fresh distilled water. The first stripping solution was collected during $0-340 \mathrm{~min}$, the second during $340-$ $1300 \mathrm{~min}$, the third during $1300-1720 \mathrm{~min}$, and the fourth during $1720-2750 \mathrm{~min}$ from the start of permeation. The results are shown in Fig. 4. Complete transport of $\mathrm{Au}(\mathrm{III})$ ions was attained after replacing the stripping solution with fresh distilled water three times. The amounts of the other elements, except for $\mathrm{Ag}$, found in the first, second, and third stripping solutions were far smaller than those obtained for the $8 \mathrm{~mol} \mathrm{dm}^{-3} \mathrm{HCl}$ feed solution. About $10 \%$ of the nuclides, irrespective of the kind of element, appeared in the fourth stripping solution as a result of membrane deterioration, as in the case of $8 \mathrm{~mol} \mathrm{dm}^{-3} \mathrm{HCl}$.

These results revealed that the membrane with a TBP/ decalin ratio of 0.27 is stable up to about $1000 \mathrm{~min}$ for $8 \mathrm{~mol} \mathrm{dm}^{-3} \mathrm{HCl}$ and up to $1700 \mathrm{~min}$ for a $1 \mathrm{~mol} \mathrm{dm}^{-3}$ $\mathrm{HNO}_{3}$ feed solution.

\section{Preparation of a multitracer solution}

On the basis of the experimental results described above, the establishment of a practical procedure for separating a multitracer from an acid solution of an $\mathrm{Au}$ target was attempted. About $1 \mathrm{~g}$ of an $\mathrm{Au}$ target irradiated by a $135 \mathrm{MeV} /$ nucleon ${ }^{14} \mathrm{~N}$ beam was dissolved in aqua regia and evaporated under reduced pressure. The residue was dissolved in $100 \mathrm{~cm}^{3}$ of $3 \mathrm{~mol}$ $\mathrm{dm}^{-3} \mathrm{HCl}$. The solution was transferred to a compartment of an apparatus (Fig. 5) which had two Teflon compartments $(80 \mathrm{~mm} \phi \times 25 \mathrm{~mm})$ separated by a supported liquid membrane containing a one-to-one TBP/ decalin solution. One hundred cubic centimeters of distilled water was filled as a stripping solution in the other compartment. Each solution was stirred by circulation with microtube pumps at a rate of $3 \mathrm{~cm}^{3}$ $\min ^{-1}$. About $50 \%$ of the Au(III) ions were transported to distilled water $3 \mathrm{~h}$ after the start of permeation; the 


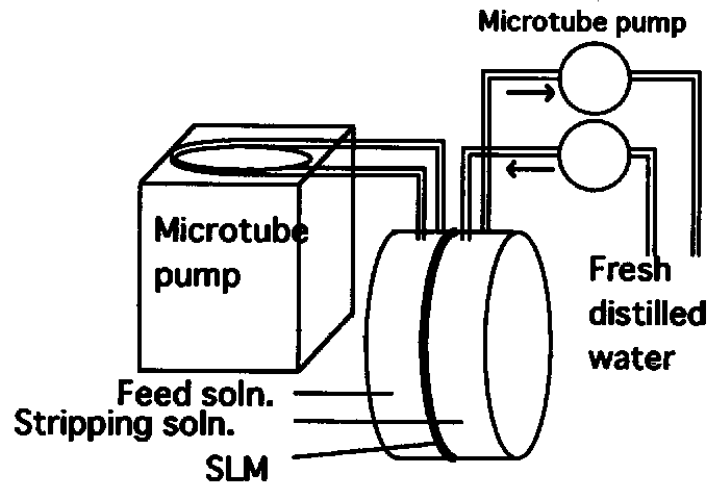

Fig. 5 Permeation apparatus.

transport increased to 90,95 , and $98 \%$ after 19,26 , and $45 \mathrm{~h}$ permeations, respectively, showing signs of saturation at the end. The complete removal of $\mathrm{Au}$ (III) ions was observed $6 \mathrm{~h}$ after replacing the stripping solution with fresh distilled water.

As described above, $\mathrm{Au}(\mathrm{III})$ ions can be transported from both $\mathrm{HCl}$ and $\mathrm{HNO}_{3}$ feed solutions. Therefore, permeation from an aqua-regia solution was examined as the final practical procedure. In this case, $4.8 \mathrm{~g}$ of $\mathrm{Au}$ target was dissolved in $20 \mathrm{~cm}^{3}$ of aqua regia. This solution was used for permeation after dilution with distilled water to $100 \mathrm{~cm}^{3}$. In order to avoid saturation, permeation was carried out with a continuous supply of fresh distilled water to the stripping-solution compartment at a rate of $2 \mathrm{~cm}^{3} \mathrm{~min}^{-1}$. Aliquots of the feed solution were withdrawn and the radioactivity of $\mathrm{Au}^{*}$ was measured using a Ge detector. Figure 6 shows the decrease of $\mathrm{Au}^{*}$ in the feed solution with the permeation time. About $99 \%$ of the Au(III) ions were removed from the feed solution within $70 \mathrm{~h}$. Only peaks due to $\mathrm{Au}^{*}$ were detected in the stripping solution, showing selective permeation of the Au(III) ions.

The procedures for preparing the multitracer used in our previous work were: (i) filtration of $\mathrm{Au}$ metal after the reduction of $\mathrm{Au}$ (III) ions with $\mathrm{H}_{2} \mathrm{O}_{2}$, leaving the multitracer in the filtrate and (ii) ethyl acetate extraction of $\mathrm{Au}$ (III) from a $3 \mathrm{~mol} \mathrm{dm}^{-3} \mathrm{HCl}$ solution. Both methods have both merits and demerits. Since $\mathrm{H}_{2} \mathrm{O}_{2}$ reduces only $\mathrm{Au}$ (III) ions to metal, radioactive nuclides of all the elements produced in the Au target remain in the filtrate. However, it requires a lot of time to completely reduce $\mathrm{Au}$ (III) ions, because a trace amount of $\mathrm{HNO}_{3}$ in the residue after the evaporation of aqua regia hinders the reduction of $\mathrm{Au}(\mathrm{III})$. Therefore, evaporation of the target solution and reduction of $\mathrm{Au}$ (III) with $\mathrm{H}_{2} \mathrm{O}_{2}$ must be repeated several times to ensure complete removal of Au(III) from the solution. Although solvent extraction of Au(III) ions with ethyl acetate is a rapid method, some $\mathrm{Fe}, \mathrm{Te}, \mathrm{Re}$, and $\mathrm{Hg}$ are coextracted into the organic phase.

The method of separating Au(III) ions by means of the supported liquid membrane developed in the present work requires about $3 \mathrm{~d}$ for an $\mathrm{Au}$ target of about $5 \mathrm{~g}$,

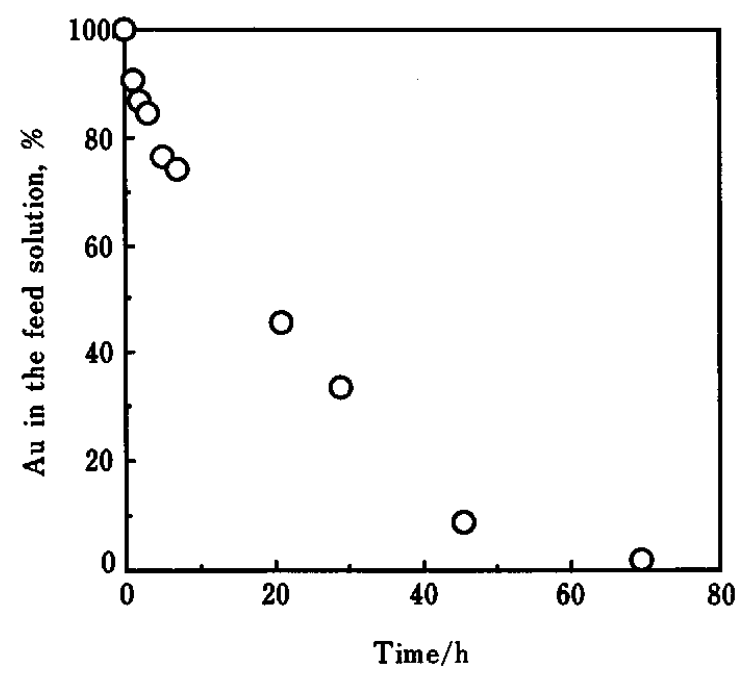

Fig. 6 Transport of $\mathrm{Au}(\mathrm{III})$ ions ( $4.8 \mathrm{~g}$ ) from a feed solution of $1.8 \mathrm{~mol} \mathrm{dm}^{-3}$ in $\mathrm{HCl}$ and $0.7 \mathrm{~mol} \mathrm{dm}^{-3}$ in $\mathrm{HNO}_{3}$ to distilled water through a membrane with a TBP/decalin ratio of 1 .

which is comparable to the time required for the reduction with $\mathrm{H}_{2} \mathrm{O}_{2}$. However, once the experimental setup is ready for permeation, the transport of $\mathrm{Au}$ (III) ions proceeds automatically. Therefore, this method can reduce the workload as well as the radiation exposure dose to researchers. The separation time will be considerably shortened by using a membrane with a large surface area, such as a hollow fiber module.

We are grateful to Drs. Y. Yano, A. Goto, and M. Kase as well as to the staff of the RIKEN Accelerator Research Facility for their cooperation in heavy-ion beam irradiation and to $\mathrm{Mr}$. S. Tanaka for his assistance in the experiment.

\section{References}

1. S. Y. Chen, S. Ambe, Y. Ohkubo, M. Iwamoto, Y. Kobayashi, N. Takematsu and F. Ambe, Anal. Sci., 7 (supplement), 1105 (1991).

2. S. Ambe, S. Y. Chen, Y. Ohkubo, Y. Kobayashi, M. Iwamoto and F. Ambe, Chem. Lett., 1992, 1059.

3. S. Enomoto, M. Yanaga, R. Hirunuma, R. Furuta, K. Endo, S. Ambe and F. Ambe, Proc. Int. Trace Anal. Symp. '94, 77 (1994).

4. M. Yanaga, S. Enomoto, R. Hirunuma, R. Furuta, K. Endo, S. Ambe and F. Ambe, Proc. Int. Trace Anal. Symp. '94, 73 (1994).

5. Y. Minai, Y. Takahashi, T. Ozaki, M. Ishibashi, S. Ambe, M. Iwamoto, M. Yanokura, H. Maeda, N. Takematsu, F. Ambe and T. Tominaga, Proc. Int. Trace Anal. Symp. '94, 71 (1994).

6. S. Ambe, S. Y. Chen, Y. Ohkubo, Y. Kobayashi, H. Maeda, M. Iwamoto, M. Yanokura, N. Takematsu and F. Ambe, J. Radioanal. Nucl. Chem. Articles, 195, 297 (1995).

7. S. Ambe, Y. Ohkubo, Y. Kobayashi, M. Iwamoto, H. Maeda and M. Yanokura, J. Radioanal. Nucl. Chem. Articles, 195, 305 (1995).

8. B. Liu, S. Ambe, S. Enomoto and F. Ambe, J. Radioanal. 
Nucl. Chem. Lett., 201, 273 (1995).

9. M. Yanaga, S. Enomoto, R. Hirunuma, R. Furuta, K. Endo, A. Tanaka, S. Ambe, M. Tozawa and F. Ambe, Appl. Radiat. Isot., in press.

10. S. Ambe, M. Iwamoto, H. Maeda and F. Ambe, $J$. Radioanal. Nucl. Chem. Articles, in press.

11. S. Enomoto, M. Yanaga, R. Hirunuma, K. Endo, S. Ambe and F. Ambe, J. Radioanal. Nucl. Chem. Articles, in press.

12. Y. Takahashi, Y. Minai, T. Ozaki, S. Ambe, M. Iwamoto, H. Maeda, F. Ambe and T. Tominaga, J. Radioanal. Nucl. Chem. Articles, in press.

13. S. Ambe, S. Y. Chen, Y. Ohkubo, Y. Kobayashi, M. Iwamoto, M. Yanokura and F. Ambe, Chem. Lett., 1991, 149.

14. S. Ambe, S. Y. Chen, Y. Ohkubo, Y. Kobayashi, M. Iwamoto, M. Yanokura and F. Ambe, Anal. Sci., 7 (supplement), 317 (1991).

15. S. Y. Chen, S. Ambe and F. Ambe, J. Radioanal. Nucl. Chem. Lett., 186, 113 (1994).

16. P. R. Danesi, R. Chiarizia and I. P. Rickert, E. P. Horwitz, Solvent Extr. Ion Exch., 3, 111 (1985).

17. R. D. Noble and J. D. Way, Liquid Membranes, ACS Symposium Series 347, American Chemical Society,
Washington, D.C., 1987.

18. P. R. Danesi, E. P. Horwitz and P. G. Rickert, J. Phys. Chem., 87, 4708 (1983).

19. K. Akiba and T. Kanno, Sep. Sci. Technol., 18, 831 (1983).

20. K. Akiba and H. Hashimoto, Anal. Sci., 2, 541 (1986).

21. M. Lemaire, A. Guy, R. Chomel and J. Foos, J. Chem. Soc., Chem. Commun., 1991, 1152.

22. S. Nakamura, S. Ohashi and K. Akiba, Bunseki Kagaku, 40, 829 (1991).

23. S. Ambe, Y. Ohkubo, Y. Kobayashi, M. Iwamoto, M. Yanokura, H. Maeda and F. Ambe, Radiochim. Acta, 63, 49 (1993).

24. J. Fu, S. Nakamura and K. Akiba, Anal. Sci., 10, 935 (1994).

25. S. Ambe, Y. Ohkubo, Y. Kobayashi, M. Iwamoto, M. Yanokura and F. Ambe, Appl. Radiat. Isot., 43, 1533 (1992).

26. T. Ishimori and E. Nakamura, Data of Inorganic Solvent Extraction (I). JAERI 1047, Japan Atomic Energy Research Institute, Tokai, 1963.

(Received November 6, 1995) (Accepted December 27, 1995) 